\title{
Can Fecal Calprotectin Reflect Your Colonic Status?
}

\author{
Rasha Ibrahim Salama ${ }^{1}$ Mohammed Hussien Ahmed ${ }^{2}$ (1) \\ ${ }^{1}$ Department of Tropical Medicine, Faculty of Medicine, Zagazig \\ University, Zagazig, Egypt \\ 2 Department of Hepatology, Gastroenterology, and Infectious \\ Disease of the Faculty of Medicine at Kafrelsheikh University, \\ Kafrelsheikh, Egypt \\ Address for correspondence Mohammed Hussien Ahmed, MD, \\ Department of Hepatology, Gastroenterology, and Infectious Disease, \\ Faculty of Medicine, KafrelsheikhUniversity, 33511, KAFR ELSHIKH, \\ Egypt (e-mail: dr.mm63@yahoo.com).
}

J Coloproctol 2022;42(1):1-6.

\begin{abstract}
Keywords

- colonic manifestations

- ulcerative colitis

- fecal calprotectin

- primary health care

- markers

Background Organic colonic manifestation may be difficult to be differentiated from functional one. Inflammatory bowel disease (IBD) is a common chronic inflammatory and destructive disease of the bowel wall. Chronic inflammation is associated with ulcerations, strictures, perforations, and it is a risk factor for dysplasia and cancer. To reduce these long-standing complications, IBD patients are in a continuous need for early diagnosis ${ }^{1}$. Markers, such as erythrocyte sedimentation rate (ESR), and c-reactive protein (CRP), fecal calprotectin ( $\mathrm{FC}$ ) have been widely used as noninvasive parameters for IBD monitoring. We aimed, in this current study, to evaluate the value of fecal calprotectin and other noninvasive biomarkers in predicting abnormal histologic findings in patients undergoing colonoscopy.in addition to determine the cutoff value which predict $\mathrm{IBD}^{2}$.

Methods The present prospective study included 160 patients with complaint of colicky abdominal pain with frequent diarrhea associated with mucous and infrequent bleeding per rectum for more than 6 months. They presented partial improvement with medication and recurrence once stopping the treatment These patients had been recently diagnosed with IBD at many primary healthcare centers covering the areas of the Kafrelsheikh and Zagazik governorate in the North of Egyptian Nile delta. After complete history, clinical examination, and laboratory investigation, they were referred to the IBD clinic at Kafrelsheikh University Hospital for assessment and ileocolonoscopy with biopsies.

Results There was a wide spectrum of age of the studied patients, with mean age $40.12 \pm 7.88$ (minimum 18 and maximum 56 years). Regarding gender, males represented $87.5 \%$ of the studied patients. Forty percent of the patients with colonic manifestation were smokers, $57 \%$ preferred a spicy diet, and the majority had low educational level (77.5\%). Forty percent had obvious blood in stool, $55 \%$ had occult blood, and raised ESR CRP occurred in $32.5 \%$ and $50 \%$, respectively. Fecal calprotectin cutoff was $>159$, with sensitivity $92.8 \%$ and specificity $97.5 \%$.
\end{abstract}

received

November 14, 2020 accepted after revision June 15, 2021 published online February 11, 2022
DOI https://doi.org/ 10.1055/s-0041-1739351. ISSN 2237-9363.

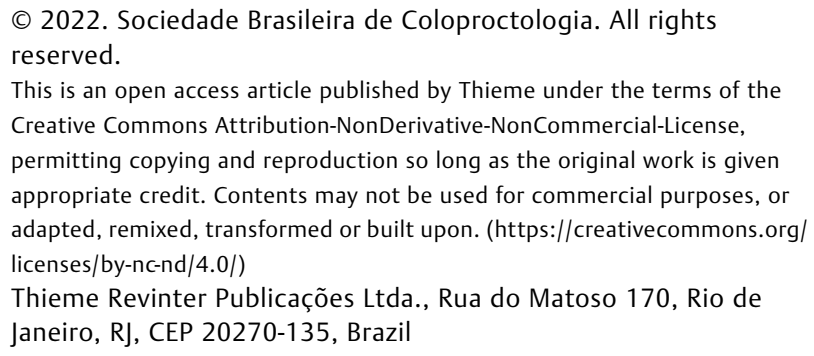

(C) 2022. Sociedade Brasileira de Coloproctologia. All rights reserved.

This is an open access article published by Thieme under the terms of the Creative Commons Attribution-NonDerivative-NonCommercial-License, permitting copying and reproduction so long as the original work is given appropriate credit. Contents may not be used for commercial purposes, or adapted, remixed, transformed or built upon. (https://creativecommons.org/ licenses/by-nc-nd/4.0/) Thieme Revinter Publicações Ltda., Rua do Matoso 170, Rio de Janeiro, RJ, CEP 20270-135, Brazil 
Conclusions: Biomarkers (FC, ESR, CRP) can be used as noninvasive parameters for the early diagnosis and prediction of organic colonic disease. Fecal calprotectin in the IBD group revealed significant area under the curve (AUC) values and cutoff $>159$, with sensitivity $92.8 \%$ and specificity $97.5 \%$.

\section{Introduction}

Organic colonic manifestation may be difficult to be differentiated from the functional type. Inflammatory bowel disease (IBD) is a chronic inflammatory and destructive disease of the gastrointestinal tract. Inflammatory bowel disease commonly affect the quality of life and result in long-term sequel. ${ }^{1}$ The optimal target in the early management of IBD is to achieve mucosal healing. A treat-to-target approach and close monitoring of the disease status improve the outcomes for those patients. $^{2}$

The standard of care for monitoring patients with IBD is endoscopy; however, experienced professionals and specialized centers are needed, and for many patients, it is a time consuming, expensive, and invasive method that requires bowel cleansing, that is, it is uncomfortable and inconvenient for many patients. Serum markers, such as erythrocyte sedimentation rate (ESR), c-reactive protein (CRP), and fecal calprotectin (FC), have been widely used as noninvasive parameters for assessing the severity and activity of IBD. ${ }^{3-5}$

Calprotectin is a calcium-binding protein that is found mainly in neutrophils and, to a lesser extent, in monocytes and reactive macrophages. It belongs to a subgroup of proteins of the S100 family (calgranulin A, S100A8; calgranulin B, S100A9; and calgranulin C, S100A12) that is associated with acute/chronic inflammatory disorders of the bowel and increasingly became available. ${ }^{6,7}$ Other tests include ESR, CRP. ${ }^{8}$

The current study aimed to evaluate the value of fecal calprotectin and other noninvasive biomarkers in predicting abnormal histologic findings in patients undergoing colonoscopy, in addition to determine the cutoff value which predicts IBD.

\section{Patients and Methods}

In the present prospective study, there were 160 patients with complaint of colicky abdominal pain with frequent diarrhea associated with mucous and infrequent bleeding per rectum for more than 6 months. They showed partial improvement with medication and recurrence of symptoms after stopping the treatment. The patients were referred from primary health care centers covering the Kafrelsheikh and Zagazik governorate and were invited to complete their endoscopic evaluation in the gastrointestinal clinic of the department of hepatology, gastroenterology and infectious diseases at the Kafrelsheikh University Hospital, Egypt, after doing noninvasive laboratory tests in the period from Jun 2019 to Jun 2020.

\section{Inclusion Criteria: Predefined as Follows}

1 - Age $>18$ years.

2- Any patient who attended our endoscopic unit between Jun 20, 2019 and Jun 20, 2020 with colonic presentations persisting for more than 6 months.

3- Patients who accepted to participate and perform all relevant investigations.

\section{Exclusion Criteria}

1- Patients previously diagnosed with IBD who had already started treatment.

2- Patients who refused follow-up and evaluation.

3- Failure to sign the informed consent.

4- Pregnant females.

\section{Baseline Evaluation}

All patients were subjected to detailed medical history and complete clinical examination. Blood samples were tested for complete blood count (CBC), ESR, CRP, serum total protein, serum albumin, and stool samples were tested for fecal calprotectin. All patients performed an ileocolonoscopic examination, and biopsies were taken from the terminal and all parts of the colon, with special attention to suspected lesions. Biopsies were sent for confirmation by histopathology.

\section{Fecal Calprotectin Measurement}

Calprotectin was measured, using quantitative enzymelinked immunosorbent assay (ELISA) (Genova Diagnostics, Asheville, NC, USA). The laboratory personnel, who were blinded from the current clinical and endoscopic disease activity of the patients, performed the analyses.

\section{Endoscopic Examination}

Endoscopy was performed under conscious sedation, in spontaneous breathing with oxygen mask support. Colonoscopy was performed by a single endoscopist at the same endoscopy unit using a Pentax EG3890 colonoscope (Pentax Medical, Tokyo, Japan) with complete examination being done up to the cecum with ileal intubation. Biopsies were taken from the ileum to exclude any histopathological disease. All parts of the colon were biopsied, with special attention to areas of suspected lesions.

An endoscopic evaluation was performed blinded to the results of the FC and other laboratories measurements.

\section{Histology}

Random mucosal biopsies were obtained from each colon segment, targeting the area of most significant mucosal disease activity. Two pathologists assessed all biopsies and reported histology utilizing a standardized checklist that 
includes histologically normal, quiescent, mild, moderate, or severe disease. Histologically normal is defined as completely normal mucosa with no features of chronicity present. Histologically nonspecific colitis is defined as having features of chronicity including chronic inflammatory cells without crypt affection or branching but no active inflammation, such as erosions, crypt abscesses or focal neutrophil infiltration. Histologically active is defined as presence of any epithelial infiltration by neutrophils, crypt abscesses, erosions or ulceration and is further classified into mild, moderate, or severe. ${ }^{9}$

\section{Follow-Up}

The patients were assessed on a monthly basis until they entered remission clinically and laboratory and endoscopically. During the follow-up visits, the following markers were measured: CBC, ESR, CRP, FC, platelets, serum total protein, hemoglobin (HB) level, and serum albumin.

\section{Statistical Analyses}

The data were collected and entered in Microsoft Excel (Microsoft Corp., Redmond, WA, USA) spreadsheets before being transferred to the SPSS for Windows, Version 16.0. software (SPSS Inc., Chicago, IL, USA) to be analyzed.

The Wilcoxon test and the paired Student $t$-test were used to compare paired data, whereas the Chi-Squared test, Fisher exact test, and the Mann-Whitney U-test were used to compare unpaired data.

\section{Results}

During the period of the current study, a total of 160 patients who fulfilled the inclusion criteria were enrolled. The age was distributed as $40.12 \pm 7.88$, with minimum of 18 and maximum of 56 years. Regarding gender, males represented $87.5 \%$ of the studied patients ( - Table 1 ).

- Table 2 shows that 40\% of the patients were smokers, $57 \%$ of cases preferred a spicy diet, and the majority had low educational level (77.5\%).

- Table 3 shows that 40\% had obvious blood in stool, 55\% had occult blood, and elevated ESR and CRP occurred in 32.5\% and $50 \%$, respectively. - Table 4) shows that $30 \%$ of the patients had IBD.

The histopathological evolution of the studied patients showed that 30\% had IBD (10\% Crohn's and 20\% ulcerative colitis) ( Table 4)

Table 1 Age and gender distribution between the studied groups

\begin{tabular}{|l|l|l|l|}
\hline \multicolumn{2}{|l|}{} & \multicolumn{2}{l|}{$\mathrm{N}$} \\
\hline \multicolumn{2}{|l|}{ Mean age \pm SD } & $40.12 \pm 7.88$ \\
\hline \multicolumn{3}{|l|}{ Median (age range) } & $40.0(18-56)$ \\
\hline \multirow{3}{*}{ Sex } & N & $\%$ \\
\cline { 2 - 4 } & Female & 140 & 87.5 \\
\cline { 2 - 4 } & Total & 20 & 12.5 \\
\hline
\end{tabular}

Abbreviation: SD, standard deviation.
Table 2 Patient's characteristics distribution between the studied groups

\begin{tabular}{|l|l|l|l|}
\hline \multicolumn{2}{|c|}{} & N & $\%$ \\
\hline \multirow{3}{*}{ Smoke } & Non & 96 & 60.0 \\
\cline { 2 - 4 } & Smoker & 64 & 40.0 \\
\hline \multirow{4}{*}{ Educt } & Non-spicy & 68 & 42.5 \\
\cline { 2 - 4 } & Spicy & 92 & 57.5 \\
\hline \multirow{5}{*}{} & LOW & 124 & 77.5 \\
\cline { 2 - 4 } & MED & 8 & 5.0 \\
\cline { 2 - 4 } & HIGH & 28 & 17.5 \\
\cline { 2 - 4 } & Total & 160 & 100.0 \\
\hline
\end{tabular}

Table 3 Stool and laboratory analysis distribution

\begin{tabular}{|l|l|l|l|}
\hline \multirow{3}{*}{ Stool } & - & $\mathrm{N}$ & $\%$ \\
\cline { 2 - 4 } & Blood & 60 & 37.5 \\
\cline { 2 - 4 } & Mucinous & 64 & 40.0 \\
\hline \multirow{3}{*}{ Occult blood } & $-\mathrm{VE}$ & 72 & 22.5 \\
\cline { 2 - 4 } & $+\mathrm{VE}$ & 88 & 45.0 \\
\hline \multirow{3}{*}{ ESR } & $-\mathrm{VE}$ & 108 & 55.0 \\
\cline { 2 - 4 } & $+\mathrm{VE}$ & 52 & 32.5 \\
\hline \multirow{3}{*}{ CRP } & $-\mathrm{VE}$ & 80 & 50.0 \\
\cline { 2 - 4 } & $+\mathrm{VE}$ & 80 & 50.0 \\
\cline { 2 - 4 } & Total & 160 & 100.0 \\
\hline
\end{tabular}

Abbreviations: CRP, C-reactive protein; ESR, erythrocyte sedimentation rate.

Table 4 Histopathology classification of the patient after endoscopy

\begin{tabular}{|c|c|c|c|}
\hline & & $\mathrm{N}$ & $\%$ \\
\hline \multirow[t]{3}{*}{ Histopathology } & Crohn's disease & 16 & 10.0 \\
\hline & Nonspecific colitis & 112 & 70.0 \\
\hline & Ulcerative colitis & 32 & 20.0 \\
\hline \multirow[t]{3}{*}{ IBD } & $-\mathrm{VE}$ & 112 & 70.0 \\
\hline & $+\mathrm{VE}$ & 48 & 30.0 \\
\hline & Total & 160 & 100.0 \\
\hline
\end{tabular}

Abbreviation: IBD, inflammatory bowel disease.

The following demographic and laboratory investigations (age, gender, smoking habits, diet, educational level, fecal calprotectin level, CRP, ESR, and occult blood in stool) were used as a noninvasive predictors because some of them showed a statically significant difference between patients in the IBD group and those in the non-IBD group. (- Table 5).

The mean fecal calprotectin level was higher among IBD patients, with a statistically significant difference between the two groups, $p$-value 0.00 . 
4 Can Fecal Calprotectin Reflect Your Colonic Status? Salama, Ahmed

Table 5 Relation with inflammatory bowel disease

\begin{tabular}{|c|c|c|c|c|c|c|}
\hline & & & Non-IBD & IBD & $t / X^{2}$ & $P$ \\
\hline \multicolumn{3}{|l|}{ Age } & $40.11 \pm 8.49$ & $40.16 \pm 6.31$ & 0.044 & 0.965 \\
\hline \multirow[t]{4}{*}{ Sex } & \multirow[t]{2}{*}{ Male } & $\mathrm{N}$ & 100 & 40 & & \\
\hline & & $\%$ & $89.3 \%$ & $83.3 \%$ & & \\
\hline & \multirow[t]{2}{*}{ Female } & $\mathrm{N}$ & 12 & 8 & 1.08 & 0.29 \\
\hline & & $\%$ & $10.7 \%$ & $16.7 \%$ & & \\
\hline \multirow[t]{4}{*}{ Smoke } & \multirow[t]{2}{*}{ Non } & $\mathrm{N}$ & 68 & 28 & & \\
\hline & & $\%$ & $60.7 \%$ & $58.3 \%$ & & \\
\hline & \multirow[t]{2}{*}{ Smoker } & $\mathrm{N}$ & 44 & 20 & 0.079 & 0.77 \\
\hline & & $\%$ & $39.3 \%$ & $41.7 \%$ & & \\
\hline \multirow[t]{3}{*}{ Diet } & \multirow[t]{2}{*}{ Non-spicy } & $\mathrm{N}$ & 40 & 28 & & \\
\hline & & $\%$ & $35.7 \%$ & $58.3 \%$ & & \\
\hline & Spicy & $\mathrm{N}$ & 72 & 20 & 12.78 & $0.002^{*}$ \\
\hline \multirow[t]{6}{*}{ Educational level } & \multirow[t]{2}{*}{ Low } & $\mathrm{N}$ & 88 & 36 & & \\
\hline & & $\%$ & $78.6 \%$ & $75.0 \%$ & & \\
\hline & \multirow[t]{2}{*}{ Med } & $\mathrm{N}$ & 4 & 4 & 1.6 & 0.44 \\
\hline & & $\%$ & $3.6 \%$ & $8.3 \%$ & & \\
\hline & \multirow[t]{2}{*}{ High } & $\mathrm{N}$ & 20 & 8 & & \\
\hline & & $\%$ & $17.9 \%$ & $16.7 \%$ & & \\
\hline \multirow[t]{6}{*}{ Stool } & \multirow[t]{2}{*}{ Normal } & $\mathrm{N}$ & 60 & 0 & & \\
\hline & & $\%$ & $53.6 \%$ & $0.0 \%$ & & \\
\hline & \multirow[t]{2}{*}{ Blood } & $\mathrm{N}$ & 20 & 44 & 77.5 & $0.00^{* *}$ \\
\hline & & $\%$ & $17.9 \%$ & $91.7 \%$ & & \\
\hline & \multirow[t]{2}{*}{ Mucous } & $\mathrm{N}$ & 32 & 4 & & \\
\hline & & $\%$ & $28.6 \%$ & $8.3 \%$ & & \\
\hline \multirow[t]{4}{*}{ Occult blood } & \multirow[t]{2}{*}{$-\mathrm{VE}$} & $\mathrm{N}$ & 68 & 4 & & \\
\hline & & $\%$ & $60.7 \%$ & $8.3 \%$ & & \\
\hline & \multirow[t]{2}{*}{$+\mathrm{VE}$} & $\mathrm{N}$ & 44 & 44 & 37.24 & $0.00^{* *}$ \\
\hline & & $\%$ & $39.3 \%$ & $91.7 \%$ & & \\
\hline \multirow[t]{4}{*}{ ESR } & \multirow[t]{2}{*}{ Normal } & $\mathrm{N}$ & 100 & 8 & & \\
\hline & & $\%$ & $89.3 \%$ & $16.7 \%$ & & \\
\hline & \multirow[t]{2}{*}{ Raised } & $\mathrm{N}$ & 12 & 40 & 80.77 & $0.00^{* *}$ \\
\hline & & $\%$ & $10.7 \%$ & $83.3 \%$ & & \\
\hline \multirow[t]{4}{*}{ CRP } & \multirow[t]{2}{*}{ Normal } & $\mathrm{N}$ & 76 & 4 & & \\
\hline & & $\%$ & $67.9 \%$ & $8.3 \%$ & & \\
\hline & \multirow[t]{2}{*}{ Raised } & $\mathrm{N}$ & 36 & 44 & 47.61 & $0.00^{* *}$ \\
\hline & & $\%$ & $32.1 \%$ & $91.7 \%$ & & \\
\hline Total & & $\mathrm{N}$ & 112 & 48 & & \\
\hline & & $\%$ & $100.0 \%$ & $100.0 \%$ & & \\
\hline
\end{tabular}

Abbreviations: CRP, C-reactive protein; ESR, erythrocyte sedimentation rate; IBD, inflammatory bowel disease.

The receiver operating characteristic (ROC) curve analysis for fecal calprotectin in the IBD group revealed significant AUC value, and cutoff $>159$ with sensitivity $92.8 \%$ and specificity $97.5 \%$ (- Table 6 - - Fig. 1).

\section{Discussion}

Our important questions are: is there a real need for the everyday use of biomarkers for differentiation between 
Table 6 Fecal calprotectin distribution between IBD and non-IBD

\begin{tabular}{|l|l|l|l|l|}
\hline & Non-IBD & IBD & t/ X & $P$ \\
\hline Fecal calprotectin & $68.96 \pm 22.8$ & $261.08 \pm 87.6$ & 17.798 & $0.00^{* *}$ \\
\hline
\end{tabular}

Abbreviations: IBD, inflammatory bowel disease.
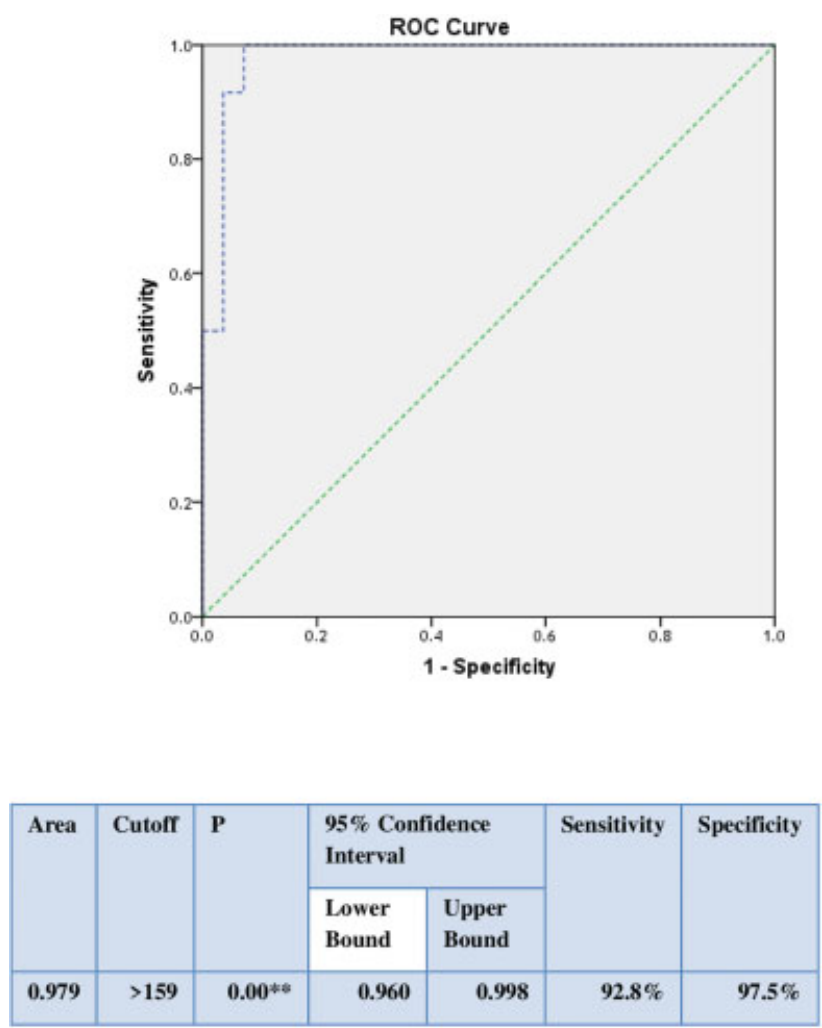

Significant AUC and cutoff > 159 with sensitivity $92.8 \%$ and specificity $97.5 \%$

Fig. 1 Receiver operating characteristic curve for fecal calprotectin cutoff regard inflammatory bowel disease.

functional and organic colonic manifestations, and: can we use fecal calprotectin as a reliable indicator of IBD? Finally, our last question was: which cutoff value we can rely on for the diagnosis of IBD?

In a country like Egypt, with limited health insurance covering facilities, a great proportion of IBD patients, mainly those in the rural countryside part of the community, lacks an easy and effective communication with specialized IBD or even gastroenterology services. Consequently, a great proportion of patients is directed to the widely available and accessible primary health care (PHC). Most of the time, available staff in these PHC centers are junior caregivers, general practitioners (GPs) or family doctors who do not have experience in or the appropriate equipment for managing patients with IBD, and this was the rationale that led us to carry out the present study, whose goal is to figure out an easy and reliable method for these juniors to manage IBD patients in the PHC setting. ${ }^{10-14}$. All of this markedly increases the need for noninvasive test for an early diagnosis. ${ }^{14}$

Still, estimation of the severity and activity of the gastrointestinal inflammation in IBD is a problematic dilemma. Endoscopy with biopsy remains the most reliable meth- od. ${ }^{15,16}$ However, the facts that the endoscopic interventions are invasive and frequently disturbing and that the symptoms are usually not conclusive have led to the use of laboratory investigations in the assessment of disease activity among IBD patients. ${ }^{17}$ Among these, acute phase reactants, ESR, CRP, occult blood in stool, and FC are the most frequently used laboratory markers because they are readily available, simple, noninvasive, relatively cheap, and have reported efficacy.

Several studies have reported that FC can be used as a diagnostic aid, and in assessment of disease remission and exacerbation. To the best of our knowledge, this is the first Egyptian report to determine the cutoff value for the diagnosis of IBD.

Vermeireetet et al., ${ }^{18}$ showed that some acute phase reactants increase in active inflammatory conditions, and CRP is among the most commonly used acute phase reactants. In the current study, we noticed that there was a significant difference between the levels of CRP, ESR, FC, and occult blood in the stool between the two groups (with and without IBD).

In the current study, the cutoff value of FC level at the time of diagnosis was $>159$, with significant AUC value, sensitivity of $92.8 \%$, and specificity of $97.5 \%$. Costa et al. ${ }^{19}$ demonstrated a 14-fold greater risk of relapse in ulcerative colitis patients if the calprotectin was higher than $150 \mathrm{~g} / \mathrm{g}$, but this was not the situation for Chron's disease patients. The difference in the mean levels may be due to poor sanitation and frequent intestinal infections in developing countries when compared to developed countries, with presumably higher level in developing countries.

One metanalysis focusing on noninvasive tests in the management of IBD in the pediatric age group found that in children whose pediatrician is considering an endoscopy, symptoms were not accurate enough to identify low-risk patients in whom an endoscopy could be avoided. Fecal calprotectin, CRP, and albumin findings were of potential clinical value, given their ability to set apart children at low risk (negative FC test result) from those at high risk (positive CRP or albumin test result) for IBD. ${ }^{20}$ If these laboratory markers are gathered together, they are useful and should be part of the global management of IBD patients. However, they are not magic, and until more data become available, the use of CRP and other laboratory markers should be seen as an additive tool to clinical observation and physical examination rather than a replacement. ${ }^{21-25}$

In conclusion, biomarkers (FC, ESR, CRP) can be used as non-invasive parameters for the early diagnosis and prediction of organic colonic disease. Fecal calprotectin in the IBD group revealed significant AUC value and cutoff $>159$, with sensitivity $92.8 \%$ and specificity $97.5 \%$. 


\section{Ethics \& Consents}

The present study was performed in accordance with the Declaration of Helsinki, Good Clinical Practice, and applicable regulatory requirements. A written informed consent was obtained from all patients after explanation of the research idea.

\section{Author Contribution}

All authors contributed equally towards formulating the idea, conception, data collection, statistics, writing, and drafting of the manuscript.

\section{Funding}

None.

\section{Conflict of Interests}

The authors have no conflict of interests with respect to the contents of this article.

\section{References}

1 El-Saka AM, Zamzam YA, Haydara T, Abd-Elsalam S. Immunohistochemical staining with chemokine panel of non-specific colitis predicts future IBD diagnosis. Cytokine 2020;127:154935

2 Romberg-Camps MJL, Bol Y, Dagnelie PC, et al. Fatigue and healthrelated quality of life in inflammatory bowel disease: results from a population-based study in the Netherlands: the IBD-South Limburg cohort. Inflamm Bowel Dis 2010;16(12):2137-2147

3 Haapamäki J, Roine RP, Sintonen H, Turunen U, Färkkilä MA, Arkkila PE. Health-related quality of life in inflammatory bowel disease measured with the generic 15D instrument. Qual Life Res 2010;19(06):919-928

4 Mahadev S, Young JM, Selby W, Solomon MJ. Quality of life in perianal Crohn's disease: what do patients consider important? Dis Colon Rectum 2011;54(05):579-585

5 Schirbel A, Reichert A, Roll S, et al. Impact of pain on healthrelated quality of life in patients with inflammatory bowel disease. World J Gastroenterol 2010;16(25):3168-3177

6 von Roon AC, Karamountzos L, Purkayastha S, et al. Diagnostic precision of fecal calprotectin for inflammatory bowel disease and colorectal malignancy. Am J Gastroenterol 2007;102(04):803-813

7 Foell D, Frosch M, Sorg C, Roth J. Phagocyte-specific calciumbinding S100 proteins as clinical laboratory markers of inflammation. Clin Chim Acta 2004;344(1-2):37-51

8 Silverberg MS, Satsangi J, Ahmad T, et al. Toward an integrated clinical, molecular and serological classification of inflammatory bowel disease: report of a Working Party of the 2005 Montreal World Congress of Gastroenterology. Can J Gastroenterol 200519 Suppl A:5A-36A

9 Neurath MF, Travis SP. Mucosal healing in inflammatory bowel diseases: a systematic review. Gut 2012;61(11):1619-1635
10 Kaplan GG, Ng SC. Understanding and Preventing the Global Increase of Inflammatory Bowel Disease. Gastroenterology 2017;152(02):313-321.e2

11 Regueiro M, Click B, Holder D, Shrank W, McAnallen S, Szigethy E. Constructing an Inflammatory Bowel Disease Patient-Centered Medical Home. Clin Gastroenterol Hepatol 2017;15(08):1148$-1153 . e 4$

12 Rubin GP, Hungin AP, Kelly PJ, Ling J. Inflammatory bowel disease: epidemiology and management in an English general practice population. Aliment Pharmacol Ther 2000;14(12):1553-1559

13 Cheung WY, Dove J, Lervy B, Russell IT, Williams JG. Shared care in gastroenterology: GPs' views of open access to out-patient followup for patients with inflammatory bowel disease. Fam Pract 2002; 19(01):53-56

14 Bennett AL, Munkholm P, Andrews JM. Tools for primary care management of inflammatory bowel disease: do they exist? World J Gastroenterol 2015;21(15):4457-4465

15 Alharbi R, Almahmudi F, Makhdoom Y, Mosli M. Knowledge and attitudes of primary healthcare physicians toward the diagnosis and management of inflammatory bowel disease following an educational intervention: A comparative analysis. Saudi J Gastroenterol 2019;25(05):277-285

16 Arthurs EA, Gholkar B, Burley K, Williams L, Lockett M. The medical management of inflammatory bowel disease in primary care: the north Bristol experience. Gut 2011;60:A130

17 Tibble JA, Sigthorsson G, Bridger S, Fagerhol MK, Bjarnason I. Surrogate markers of intestinal inflammation are predictive of relapse in patients with inflammatory bowel disease. Gastroenterology 2000;119(01):15-22

18 Vermeire S, Van Assche G, Rutgeerts P. C-reactive protein as a marker for inflammatory bowel disease. Inflamm Bowel Dis 2004; 10(05):661-665

19 Costa F, Mumolo MG, Ceccarelli L, et al. Calprotectin is a stronger predictive marker of relapse in ulcerative colitis than in Crohn's disease. Gut 2005;54(03):364-368

20 Holtman GA, Lisman-van Leeuwen Y, Reitsma JB, Berger MY. Noninvasive Tests for Inflammatory Bowel Disease: A Metaanalysis. Pediatrics 2016;137(01):

21 Vermeire S, Van Assche G, Rutgeerts P. Laboratory markers in IBD: useful, magic, or unnecessary toys? Gut 2006;55(03):426-431

22 Aomatsu T, Yoden A, Matsumoto K, et al. Fecal calprotectin is a useful marker for disease activity in pediatric patients with inflammatory bowel disease. Dig Dis Sci 2011;56(08):2372-2377

23 Kristinsson J, Armbruster CH, Ugstad M, et al. Fecal excretion of calprotectin in colorectal cancer: relationship to tumor characteristics. Scand J Gastroenterol 2001;36(02):202-207

$24 \mathrm{MH}$ Ahmed, MH Emara, EM Saeed, etal. How Valuable are Noninvasive Tests as? Indicators of IBD Activity and Severity in? the Primary Health Care??. Afro-Egyptian Journal of Infectious and Endemic 2021;11(02):113-119

25 Kristensen V, Røseth A, Ahmad T, Skar V, Moum B. Fecal Calprotectin: A Reliable Predictor of Mucosal Healing after Treatment for Active Ulcerative Colitis. Gastroenterol Res Pract 2017; 2017:2098293 